\title{
ICT and Human Development in Selected Devolving Countries
}

\section{Arash Ketabforoush Badri ${ }^{18}$ Parsa Ketabforoush Badri ${ }^{2}$ Mostafa Cham ${ }^{3}$}

\begin{abstract}
Human development and planning is one of the most prominent activities in any country. There are several factors that can be effective in achieving this. One of the key elements in this way is ICT. In recent decades, this technology has evolved widely across all social and economic spheres and has had a profound impact on organizations, human resources and the economics of micro and macro societies. Considering the impact of using information and communication technology can be a good way to increase the level of productivity and development of each country. The purpose of this paper is to investigate the impact of information and communication technology on human development index. Therefore, the investigated model has been using panel data for 15 selected developing countries over the period of 2012 to 2017. The estimation results show that ICT has a positive and significant effect on human development index. While foreign direct investment and value added have a positive impact and inflation has a negative impact on the human development index.
\end{abstract}

JEL Classification:

C23; EO1.

Accepted: 1 October 2019

Published: 14 October 2019

Funding: This study receive no specific financial support.

Competing Interests: The authors declare that they have no competing interests.

\section{Introduction}

Information and Communication Technology (ICT) is the knowledge that has broken all the barriers and geographical boundaries across the five continents and affected all socio-economic, political, military and cultural dimensions (Shojaee \& Beigi, 2010).

The developments that have happened over the last decade of the twentieth century were unprecedented in the history of science and industry because the achievements of the Industrial Revolution and the Electronic Revolution merged with the developments of Information Technology and the founding of ICT (Dizaji \& Ketabforoush, 2012).

ICT has always been a key factor in economic and social development and plays an important role in these areas. It is now widely recognized that the main reason for developing countries' slowdown in social, economic and even cultural development is their inability to identify or develop appropriate technology and exploit it in productive activities. The scope and impact of this technology in today's life has become so one of the most important topics in the world today and has attracted the attention of many countries around the world (Latif et al., 2017).

The rapid growth of ICT in the global production of goods and services affects all markets and penetrates the whole society. ICT is also a key driver of economic growth through increased productivity and human development. Obviously, ICT changes in addition to affecting productivity change the types of jobs, skills, and responsibilities and workforce tasks within organizations, institutions, and the society (Dizaji \& Ketabforoush, 2012).

Recent advances in ICT have made countries and organizations more inclined to use modern technologies to achieve organizational goals and value creation. Today's human beings experience an ICT-based society 
that has its own characteristics. Living in the new world requires a thorough understanding and acquisition of the skills to use these technologies, and without such tools, it will be difficult to compete and lead to the loss of many opportunities in the daily lives of individuals and communities ( $\mathrm{Lu}, 2018$ ).

Organizations should also have the necessary background to optimally deploy and utilize ICT so that they can take important and correct steps in the field of development and ensure organizational life (Ketabforoush, Taheri, \& Yahyavi, 2015). So it can be said that exploring the impact of new technologies on workforce employment and how to best allocate human resources is considered a necessity in today's world (Asongu, Nwachukwu, \& Pyke, 2019).

Today's world is more than ever bound by a constant and unavoidable phenomenon whose intensity, speed, and uncertainty have been astonishing with the phenomenon of globalization, which is called change, and exists in all economic, political, social, and cultural contexts. Investigating, recognizing, anticipating and adapting to these environmental changes requires appropriate plans and strategies with a vision for the future and a vision of creativity and innovation that is essential for any organization, manufacturing firm and, ultimately, for each country. ICT as a comprehensive phenomenon affects the full spectrum of human activities from personal application to economic and political activities. Because it is considered as a versatile, flexible and versatile tool (Asongu \& Boateng, 2018).

ICT is one of the important aspects of this global change. Significant developments in the field of ICT examine these changes in terms of intra-organizational, inter-organizational, and economic, cultural, educational, and value-creating aspects of audiences that ultimately improve the quality of products and services and increase speed and accuracy, reduces costs, and improves overall productivity (Bahari, Ansari, \& Sohrabi, 2010).

Also, the importance of using technologies and the need to understand the factors and phenomena affecting the use of these tools has been advanced to the degree that today one of the most important attitudes towards poverty reduction in the world is the development and promotion of the adoption of new technologies in less developed areas (Arslan, Bagchi, \& Kirs, 2019).

To this end, the present study is an attempt to investigate how ICT affects human development in 15 selected developing countries over the period of 2012 to 2017.

\section{Theoretical Foundations and Previous Studies}

\subsection{Concept of ICT}

The information society was first used by Mulchup and Porat in the 1970s. Since then, the concept of information has been considered an important factor in the development process. With the emergence of this concept, technologies have emerged for communication and the process of receiving, transmitting and analyzing information known as ICT (Ketabforoush et al., 2015).

The role of these technologies in the development of societies has become so widespread that many experts have used the concept of information and related technologies to explain the differences in degree of development between countries and have shown that ICT may be provided through Inexpensive and efficient tools to accelerate the process of gathering and evaluating information (Trug, 2007).

\subsection{Human Development Index (HDI)}

The Human Development Index (HDI) is a composite index that measures a country's average across three key areas of life expectancy and health (measured by the birth-expectancy index); knowledge (measured by adult literacy rates) and measures enrollment rates in elementary, middle and high school) and standard of living (measured in terms of GDP in terms of purchasing power in US dollars) of human development. Therefore, overall human development index is calculated from the weighted combination of three birth-rate (year), education (percent), and GDP per capita. ICT can affect all three areas of HDI and increase its level.

2.3. Effects of ICT on HDI

2.3.1. The Effect of ICT on Life Health

ICT can affect HDI in three ways. Organizing and delivering effective health care requires coping with the huge amount of information and ICT can provide as an extremely useful tool for the health care industry and increasing health (Rudowski, 2007). Hospital Information Systems, Medical Care Information Systems, Health Information Systems, Electronic Records, Artificial Intelligence and Automated Consulting, Diagnostic and Therapeutic Services, Dental Medicine, Telemedicine and many more resulting from the use of ICT in health and treatment that raises the level of life expectancy at the community level, are to be mentioned. The mentioned technologies raise the health of life and ultimately increases the level of HDI in the community.

\subsubsection{The effect of ICT on Knowledge}

We may say that the mission of ICT is to provide the required facilities and infrastructure to produce and distribute knowledge. The advances of today's world and the use of computers and the Internet have made it possible for people to get the latest information they need in any field, with advanced facilities and information 
and the ability to communicate and exchange information wherever they are. But undoubtedly, the greatest impact of the emergence of ICT on educational environments and schools has led to educational environments leading to virtualization and facilitating the use of knowledge. Because of the availability of ICT in many schools and training centers, the level of education in the community can increased. The creation of virtual libraries and distance education is one of the important features and applications of ICT in recent years, which has also increased the level of education and literacy at the community level and raised the level of HDI. It can be argued that the mission of ICT is to provide the required facilities and infrastructure in order to produce and distribute knowledge. The advances of today's world and the use of computers and the Internet have made it possible for people to get the latest information they need in any field; with advanced facilities and information and the ability to communicate and exchange information wherever they are, but undoubtedly, the greatest impact of the emergence of ICT on educational environments and schools has led to educational environments leading to virtualization and facilitating the use of knowledge (Scheuermann \& Pedro, 2009). Because of the presence of ICT in many schools and training centers, the level of education in the community can increase. The creation of virtual libraries and distance education has been one of the important features and applications of ICT in recent years, which has also increased the level of education and literacy at community level and raised the level of HDI.

\subsubsection{The Effect of ICT on Living Standards}

ICT can also affect the standard of living. ICT increases productivity. Increasing productivity due to the impact of ICT is possible in three ways; first, ICT changes drive growth in the innovation sector. Second, lowering the prices of new means of production by innovative sectors of the economy deepens capital in largescale economy and ultimately reorganizes production for capital goods into new technologies. Increasing the power and speed of data generation, the relative cheapness of hardware and software and the use of mechanized systems creates optimal information systems and fast and easy access to information, the ability to calculate and exchange data at high speeds in a geographical area. It has become wider and has simultaneous access to information resources. These developments have led to major changes in the way we do business and the emergence of e-commerce and ICT-related businesses and industries. In this situation, not only will the cost of production of the enterprises reduce, but also the increase of business efficiency and the exchange of electronic means will increase the production, value added and profit of the enterprises. This will increase GDP and lead to a higher GDP per capita, an increase in the standard of living, and ultimately an increase in HDI. Therefore, ICT as an important factor in increasing HDI should be considered in planning and policymaking.

\subsection{Previous Studies}

Bahrini and Qaffas (2019) studied effect of ICT on economic growth of 14 countries in the MENA ${ }^{1}$ and 31 countries in the $\mathrm{SSA}^{2}$ regions by using a panel $\mathrm{GMM}^{3}$ method over the period 2007-2016. The results show that except fixed telephone, other ICT such as mobile phone, Internet usage, and broadband adoption have effects on economic growth in studied countries.

Batool et al (2019) investigated the role of ICT in resource management. The results show that from the economic point of view, the Wavelet method shows that ICTs help to reduce long-term and long-term environmental degradation in the South Korean economy. This underscores the importance of policymakers' organized strategies to counter the two to three years of massive environmental degradation in South Korea.

Niebel (2018) examined the effects of ICT on economic growth in 59 developing countries by using panel data over the period 1995-2010. The results showed that there is a positive and significant relationship between ICT and economic growth in the countries under study.

Albiman and Sulong (2016) studied the effects of ICT on economic growth over the period 1990 to 2014 in the SSA countries. The results show that ICT indicators in this study were the number of telephone lines, the number of mobile phones and the Internet had a positive impact on the economic growth of the countries under study.

Ketabforoush, Ketabforoush, and Yahyavi (2016) studied impacts of using ICT on environment in 13 MENA countries during 2005-2013 by using the panel data method. The results of the estimates indicate that using of ICT can improve environmental quality in the studied countries. This issue indicates a direct relationship between the use of ICT and the quality of the environment. Also, human capital and health expenditures have positive impacts on the environment.

Pradhan, Mak, and Neville (2015) examined effects of ICT and financial development on economic growth. The results show that in the long run ICT infrastructure has been able to contribute to the economic growth of West Asian countries. However, financial development has not a significant impact on the economic growth of these countries.

\footnotetext{
Middle East and North Africa (MENA).

2. Sub-Saharan Africa (SSA)

. Generalized Method of Moment (GMM).
} 
3. Material and Methods

3.1. Data and Statistics

The statistical society of this study included 15 developing countries Bangladesh, Bolivia, Chile, Colombia, Iran, Jordan, Egypt, Turkey, Morocco, Malaysia, Pakistan, Philippines, Tunisia, Colombia and Uruguay. The period studied is 2012 to 2017. Time series data from these countries were collected from WDI2018. In this study, the following equation is used to estimate the effect of ICT on HDI:

$\mathrm{LHDI}_{i}=\beta_{0}+\beta_{1} L\left(\mathrm{ICT}_{i}\right)+\beta_{2} L\left(\mathrm{FDI}_{i}\right)+\beta_{3} L\left(\mathrm{VA}_{i}\right)+\beta_{4} L\left(\mathrm{P}_{i}\right)$

$\mathrm{LHDI}_{\mathrm{i}}=$ Logarithm of Human Development Indicator i.

$\mathrm{LICT}_{\mathrm{i}}=$ Logarithm of country telephone lines i.

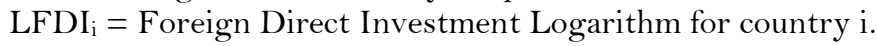

$\mathrm{LVA}_{\mathrm{i}}=$ Logarithm Value Added of country i in US dollars.

$\mathrm{LP}_{\mathrm{i}}=$ Logarithm of country Inflation $\mathrm{i}$.

\subsection{Panel Data}

Panel data model is one of the most used methods in Econometric for estimating equations and economic relations. This model are a combination of cross-sectional data and time series, that's mean we can see Information on cross-sectional data over time. Clearly, such data has two dimensions. One dimension is related to different units in any given time period and the other is related to time. Using panel data methods than the cross-sectional and time-series methods have two major advantages. First, it allows the researcher to investigate relationship between variables and even units (countries) to consider and review over time and the second advantage is the ability of the method to control individual effects related to countries (as of period). The larger number of observations and data, in panel data method compared with other models, more reliable estimates, and testing the enhanced model by researcher are the other features of panel data model (Ashrafzadeh \& Mehrgan, 2010).

\section{Empirical Analysis}

4.1. Results of $F$ and Houseman Tests

Table 1 shows the results of $\mathrm{F}$ and Housman tests. Based on the results, random effects will be used in estimation of the model.

Table-1. Results of the $\mathrm{F}$ and Hausman estimation model.

\begin{tabular}{c|c|c}
\hline Test & F test & Hausman test \\
\hline Statistic & 220.7605 & 1.8318 \\
\hline probability & 0.0000 & 0.8719 \\
\hline
\end{tabular}

4.2. The Estimation Results

Accordingly, the estimation results of the proposed model to determine the pattern of ICT effect on HDI using panel-data random effects method are presented in Table 2.

Table-2. Results of the estimation of ICT effects on HDI.

\begin{tabular}{c|c|c|c}
\hline Variables & Coefficient & T statistic & Probability \\
\hline LICT & 0.0490 & 7.6382 & 0.0000 \\
\hline LFDI & 0.0381 & 3.7868 & 0.0003 \\
\hline LVA & 0.0259 & 7.4499 & 0.0000 \\
\hline LP & -0.0566 & -3.1031 & 0.0032 \\
\hline \multicolumn{2}{c}{$R^{2}=0.9817$} & $\overline{R^{2}}=0.9776$ & D-W $=1.89$ \\
\hline
\end{tabular}

It must be noted that due to the logarithm of the model under study, the coefficients of the variables indicate the elasticity. As the results show, the HDI elasticity to ICT is 0.04. This means that as a result of one percent increase in ICT, HDI will increase (or decrease) 0.04 percent, which is in agreement with economic theories and is statistically significant. It can be concluded that ICT is effective on HDI. The increasing use of ICT in three dimensions of health, knowledge and standard of living can affect HDI. ICT can be used in such areas as hospital information systems, medical care information systems, health information systems, electronic records, artificial intelligence and automated consulting, diagnostic and therapeutic services, telemedicine, telemedicine and many more. Others have argued that this is due to the use of ICT in healthcare, which raises the level of life expectancy at the community level, which raises the health of life and ultimately increases the level of HDI in the community. Because of ICT in many schools and training centers, the level of education in society can be increased. The creation of virtual libraries and distance education has been one of the important features and applications of ICT in recent years, which has also increased the level of education and literacy at the community level and raised the level of HDI. ICT increases productivity. By increasing productivity and producing quality products, GDP will increase and lead to higher GDP per capita, an 
increase in the standard of living, and ultimately an increase in HDI. Therefore, ICT as an important factor in increasing HDI should be considered in planning and policy making. In addition, it could be concluded from Table 2 that FDI has a positive and significant effect on HDI equal to 0.03 . Which means, with a $1 \%$ increase in foreign direct investment, the Human Development Index improves 0.03\%. FDI is one of the most important factors affecting economic growth and development in the world. Technology transfers, the supply of scarce resources such as physical and human capital, research and innovation, increased management capacity and skills, the exploitation of opportunities, etc. are among the benefits of foreign direct investment in countries that cannot be denied. Trade liberalization and the expansion of trade volume, in addition to its direct effects on human development, by improving economic growth, improve human development indicators. The economic growth that comes from expanding the volume of trade also makes it easier for people to access health and education services and promote human development. The elasticity of HDI to value added is 0.02 , indicating a positive and significant relationship between value added and HDI. Increased value added and industrialization are achieved through the development and use of tools, machines and energy, with division of labor, specialization and standardization. This concept is shaped by the use of science in development and technology in production, and creates order, discipline, and the system of collective labor in society to integrate individual power and talent and increase collective labor productivity. Industrialization requires the creation of facilitation, support and development institutions in the human, cultural, technological and financial fields. Industrialization enhances productivity in various socio-economic sectors such as agriculture, health and education. Estimated elasticity of inflation variable is -0.05 and negative. This means that with a $1 \%$ increase in inflation, HDI will decrease by $0.05 \%$. Inflation variable is economically and statistically significant. The most important effect of inflation is on the distribution of income and wealth. One prominent feature of the phenomenon of inflation is the disproportionality between changes in prices and incomes.

As a result, the price of some commodities and the income of some classes and groups of society will increase at a fast pace, while this song is slow for other classes and classes of society. This disproportionality will increase the real income of some people in the community, including variable income holders such as traders, landowners, and freelancers, and instead of those who have a steady income. Inflation, of course, can transform the portfolio of economic agents because as a result of inflation, individuals and groups try to reduce their cash assets as much as possible, and in turn increase the share of their non-cash goods and property. Thus, much of the time, energy, and financial resources of people and economic agents are spent on activities that are designed to adapt to inflationary conditions and to avoid asset devaluation rather than pursuing profitable and productive activities. Promotes game dealers or speculative deals. Therefore, it can be concluded that inflation may even affect economic efficiency. Other effects of inflation include its impact on saving and consumption. As a result of the devaluation of the national currency as a result of rising inflation, all those who hold their cash in savings will be adversely affected, which has a negative effect on people's desire for savings and, as mentioned, in inflationary terms, the desire for goods sustainable capital such as land and housing will increase, which could affect the type of consumption. The other effect of inflation is its impact on business decision-making, which can make economic agents uncertain in their decision making, as inflation makes it difficult for firms to estimate income and costs. The subsequent impact of inflation can be seen in current government spending. Because the government itself is a consumer and on the other hand, it has to pay its employees. All of this can have a negative impact on the human development index in countries. The $R^{2}$ estimated by the model is 0.98 . This indicates the high explanatory power of the independent variables and indicates a high percentage of confidence in the results. There is no correlation between the estimated selfcorrelation model and the Durbin-Watson 1.89 confirms this.

\section{Conclusion}

ICT has undoubtedly brought about widespread developments in all economic and social fields in recent decades. The scope and impact of this technology in today's life has become so one of the most important topics in the world today and has attracted the attention of many countries around the world. This technology has a wide impact on the economy of society. The purpose of this study was to investigate the effect of ICT on human development index. In this regard, the impact of ICT on human development index among 15 selected developing countries was investigated using panel data method from 2012-2017. The statistical society of this study included 15 developing countries Bangladesh, Bolivia, Chile, Colombia, Iran, Jordan, Egypt, Turkey, Morocco, Malaysia, Pakistan, Philippines, Tunisia, Colombia and Uruguay. The results showed that ICT had a positive effect on HDI. Foreign direct investment also had a significant positive impact on the HDI. Also the value added has had a positive effect on HDI. While inflation has had a significant and negative impact on HDI, as inflation increased, HDI decreased.

\section{References}

Albiman, M., \& Sulong, Z. (2016). The role of ICT use to the economic growth in Sub Saharan African region (SSA). Journal of Science and Technology Policy Management, 7(3), 306-329.

Arslan, F., Bagchi, K. K., \& Kirs, P. (2019). Factors implicated with firm-level ICT use in developing economies. Journal of Global Information Technology Management, 22(3), 179-207. 
Ashrafzadeh, H., \& Mehrgan, N. (2010). Econometric panel data. Tehran: Taavon Institute.

Asongu, S. A., \& Boateng, A. (2018). Introduction to special issue: Mobile technologies and inclusive development in Africa. Journal of African Business, 19(3), 297-301.

Asongu, S. A., Nwachukwu, J. C., \& Pyke, C. (2019). The comparative economics of ICT, environmental degradation and inclusive human development in Sub-Saharan Africa. Social Indicators Research, 143(3), 1271-1297.

Bahari, N., Ansari, M., \& Sohrabi, B. (2010). Investigating the role of cultural ICT in improving management case study: Tehran municipality cultural and art organization. Journal of Library and Information Science and Technology, 3(11), $1-15$.

Bahrini, R., \& Qaffas, A. A. (2019). Impact of information and communication technology on economic growth: Evidence from developing countries. Economies, 7(21), 1-13. Available at: 10.3390/economies7010021.

Dizaji, M., \& Ketabforoush, B. A. (2012). The impact of ICT expenditure on national production in Iran and selected countries. Paper presented at the Proceedings of the First International Conference on Management, Innovation and Production. Qom. September, 2012.

Ketabforoush, B. A., Ketabforoush, B. A., \& Yahyavi, R. (2016). Examination of the quality of environment in MENA countries with emphasizing using of ICT. Noble International Journal of Social Sciences Research, 1(1), 11-15.

Ketabforoush, B. A., Taheri, M., \& Yahyavi, R. (2015). Assessing the impact of ICT on the quality of the environment in Iran and the countries of the Persian Gulf. The Open Access Journal of Resistive Economics (OAJRE), 34(3), 45-53.

Latif, Z., Xin, W., Khan, D., Iqbal, K., Pathan, Z., Salam, S., \& Jan, N. (2017). ICT and sustainable development in South Asian countries. Hum Syst Manag, 36(4), 353-362.

$\mathrm{Lu}, \mathrm{W}$. C. (2018). The impacts of information and communication technology, energy consumption, financial development, and economic growth on carbon dioxide emissions in 12 Asian countries. Mitig Adapt Strateg Glob Chang, 2(4), 115 .

Niebel, T. (2018). ICT and economic growth - comparing developing, emerging and developed countries. World Development, 104, 197-211. Available at: https://doi.org/10.1016/j.worlddev.2017.11.024.

Pradhan, R. P., Mak, B. A., \& Neville, R. N. (2015). The dynamics of information and communications technologies infrastructure, economic growth, and financial development: Evidence from Asian countries. Technology in Society, 42(2), 135-149.

Rudowski, R. (2007). Impact of information and communication technologies (ICT) on health care, department of medical informatics and telemedicine medical university of Warsaw: Saluti Pablication.

Scheuermann, F., \& Pedro, F. (2009). Assessing the effects of ICT in education. European Union/OECD, Joint Research Centre, Luxembourg.

Shojaee, N., \& Beigi, T. (2010). The relationship between ICT and Iranian economic growth using endogenous growth models. Journal of Industrial Management, 15(11), 114-101.

Trug, T. (2007). Trade liberalization and development in ICT sector and its impact on household welfare in Vietnam. DEPOCEN Working Paper Series, No. 2008/34. 